\title{
Radical prostatectomy is the most cost-effective primary treatment modality for men diagnosed with high-risk prostate cancer
}

\author{
Yves Fradet, MD, FRCSC \\ Professor of Surgery/Urology, Université Laval, Québec, QC
}

\section{$\mathrm{T}$} his year in Canada 26500 men will receive a diagnosis of prostate cancer and will be faced with the complex decision about the type and timing of primary treatment. In no other cancer is there such a lack of consensus about the optimal management of patients according to their risk category. Primary treatment offerings for prostate cancer vary from active surveillance, radical prostatectomy (RP), external-beam radiation therapy (EBRT), brachytherapy or androgen-deprivation therapy (ADT) and diverse guidelines draw no conclusion regarding the relative efficacy of these alternatives. The most important fear of a man diagnosed with prostate cancer is that of dying from the cancer after suffering from a protracted metastatic condition. Selecting a treatment modality that can best minimize these risks should be the priority, provided that the risk is well-understood by the patient.

D'Amico was the first to propose a simple risk classification based on pre-treatment criteria that could predict prostate cancer-specific mortality (PCSM) after primary treatment. ${ }^{1}$ This widely used classification defines high risk as Gleason 8-10 on biopsy or prostate-specific antigen (PSA) $>20$ or stage cT2C. Relative-to-low risk and intermediaterisk patients treated with RT or RP have a 5-fold higher PCSM; similarly treated high-risk patients have a 14 -fold higher PCSM.

The opinion often expressed is that "RT and hormonal therapy are now the accepted standard treatments for patients with locally advanced prostate cancer because of the survival benefit shown in a randomized trial" (Level 1 evidence) comparing with RT alone. ${ }^{2}$ Ironically, this sentence comes from D'Amico in a 2003 publication which was the first to show, in intermediate- and high-risk groups treated during the PSA era, more than twofold higher PCSM in 2370 patients treated with modern RT compared to 4946 patients treated by RP, despite a significantly older population in the RT group (median 71.3 years in the RT group vs. 63.5 years in the RP group). ${ }^{1} \mathrm{In}$ fact, surgery is the only treatment that has been compared to observation in a Swedish ${ }^{3}$ and a United States trial. ${ }^{4}$ The U.S. Prostate Cancer Intervention Versus Observation Trial showed no benefit of surgery overall, which is no surprise given that $>75 \%$ of patients had a low risk prostate cancer at randomization and a high 10- and 15-year mortality by any cause of $40 \%$ and $60 \%$, respectively. Despite these limitations, in the $20 \%$ of patients that had a Gleason $\geq 7$, RP reduced the PCSM by $60 \%$ (HR $0.4 \mathrm{Cl} 0.16-1.0$ ) which should become significant with longer follow-up. Similarly, in an individualized estimation of the benefit of RP in the Scandinavian trial, Vickers and colleagues concluded that RP unequivocally benefits patients with Gleason 8 cancers or Gleason 7 and clinical stage T2 (2 of 3 D'Amico intermediate-risk factors). ${ }^{5}$

The CaPSURE (Cancer of the Prostate Strategic Urologic Endeavor) registry, that has monitored longitudinally the outcome of prostate cancer patients who received treatment at any of 40 (primarily community-based) urology practices across the U.S., shows that RP has been the primary treatment for $42 \%$ of patients with high-risk cancer. This proportion has not significantly changed between 1990 and 2007, while EBRT or brachytherapy went from $26 \%$ to $17.5 \%$ and ADT alone from $18.5 \%$ to $29 \% .{ }^{6}$ In Canada, our group has been advocating RP as a valuable treatment option for highrisk prostate cancer patients for a few decades. Our results, first reported in 2008 , showed that up to $25 \%$ of high-risk patients have organ-confined cancer at final pathology after $\mathrm{RP}$ and their 10-year biochemical recurrence (BCR) was 30\% and PCSM 3.8\%. ${ }^{7}$ The 10-year BCR for the whole cohort of high-risk patients treated by RP was $65 \%$ and PCSM $10 \%$. As individual risk factors, PSA $>20$ was the least predictive of PCSM with only $4.5 \%$ at 10 years, compared to $9.2 \%$ for cT2c+ and $18.2 \%$ for Gleason $8+$. These outcomes seem highly reproducible between high-volume centres. In a recent report combining data on $>23000$ patients treated 
by RP at 5 academic U.S. institutions, the 10-year PCSM for Gleason 8 was also $18 \% .^{8}$

So, is there evidence that one treatment modality is superior at reducing PCSM? Short of any report on randomized studies across primary treatments, the best evidence to date comes from 6 observational studies - all of which have reported improved PCSM and/or overall survival among patients treated with RP compared to EBRT. A European study performed by epidemiologists showed a 2.3-fold increased PCSM in men treated by EBRT versus RP. ${ }^{9}$ They concluded that "surgery offers the best chance for long-term prostate cancer specific-survival, in particular for younger patients and patients with poorly differentiated tumors." In the same year, Albertsen and colleagues analysed outcomes of 1618 men in the Connecticut Tumor Registry who were diagnosed in the early PSA era, adjusting for D'Amico risk classification and comorbidity. ${ }^{10}$ Again, men treated by EBRT had a 2.2-fold increased PCSM compared to RP after a median follow-up of 13 years. Also in 2007, Tewari and colleagues reported outcomes of a large cohort of high-grade prostate cancer patients which showed a $54 \%$ and $49 \%$ lower all-cause and PCSM for patients treated by RP versus EBRT. ${ }^{11}$ In 2010, there were two important studies. The first study analyzed outcomes of 7538 men from the CaPSURE registry and showed that the PCSM relative to prostatectomy was 2.2 for EBRT and 3.2 for ADT. ${ }^{12}$ The authors concluded that "although this was not a randomized study, given the multiple adjustments and sensitivity analyses, it is unlikely that unmeasured confounding would account for the large observed difference in survival." The critiques will say that RT has improved and that results should be better in recent years. The second study by Zelefsky and colleagues reported the 8-year metastasis-free survival of a prospective cohort of 1318 patients treated by RP at Memorial Sloan-Kettering Cancer Center and 1062 treated by intensity-modulated radiation therapy (IMRT) delivering $>80 \mathrm{~Gy}$ in all patients. ${ }^{13}$ $\mathrm{RP}$ reduced the risk of metastasis by $65 \%$ and the PCSM by $68 \%$. Finally, Kibel and colleagues recently reported on a cohort of 10429 patients treated between 1995 and 2005 at the St. Louis and Cleveland clinic with only $12 \%$ of patients being high risk. ${ }^{14}$ Using a propensity score analysis, EBRT was associated with a 1.6-fold risk of all-cause mortality and 1.5 -fold risk of PCSM overall.

Thus it would seem appropriate to conclude that all patients facing the choice of treatment for high-risk prostate cancer should be informed that, based on available evidence, RP as primary treatment will reduce at least 2-fold their PCSM and risk of metastasis. Obviously, patients with BCR after RP can benefit from salvage EBRT. We recently reported similar long-term results on mortality and metastasis in patients with positive surgical margin treated with salvage EBRT at a median PSA $<0.5$ compared to patients with negative margins. ${ }^{15,16}$ Even when including the cost of salvage EBRT, RP remains significantly less expensive than EBRT for this group of patients, as more than one third of high-risk patients will not experience BCR and thus not receive $A D T$. In addition to a higher cost of the primary treatment, all patients treated with EBRT for high risk will receive at least 6 months of ADT in addition to long-term ADT upon BCR.

RT of prostate cancer is a moving target and several radiation therapists are now offering combined treatments that include brachytherapy, IMRT and ADT for high-risk patients on the basis that it allows the delivery of higher radiation dose levels to the prostate. These treatments should be presented as experimental, given the fact that despite previous increments in dose delivered to the prostate, the impact has not been translated into better PCSM compared to RP. One must also be cautious in judging the efficacy of EBRT on BCR as it has been recently shown that BCR after EBRT was associated with a 1.5-fold ( $p=0.006)$ increase in PCSM compared to BCR after RP. ${ }^{17}$ Patients must also be aware of the nature and severity of potential complications with these "new" treatments. Finally, one must remember that radiation treatments can be associated with an increased risk of secondary cancers, particularly in patients with a long survival as is the case for most prostate cancer patients even with high-risk disease.

Competing interests: None declared.

This paper has been peer-reviewed.

\section{References}

1. D'Amico AV, Moul J, Carroll PR, et al. Cancer-specific mortality after surgery or radiation for patients with clinically localized prostate cancer managed during the prostate-specific antigen era. J Clin Oncol 2003;21:2163-72. http://dx.doi.org/10.1200/JC0.2003.01.075

2. Bolla $M$, Collette $L$, Blank $L$, et al. Long-term results with immediate androgen suppression and external irradiation in patients with locally advanced prostate cancer (an EORTC study): A phase III randomised trial. Lancet 2002;360:103-6. http://dx.doi.org/10.1016/S0140-6736(02)09408-4

3. Bill-Axelson $\mathrm{A}$, Holmberg $\mathrm{L}$, Ruutu $\mathrm{M}$, et al. Radical prostatectomy versus watchful waiting in early prostate cancer. N Engl J Med 2011;364:1708-17. http://dx.doi.org/10.1056/NEJMoa1011967

4. Wilt TJ, Brawer MK, Jones KM, et al. Radical prostatectomy versus observation for localized prostate cancer. N Engl J Med 2012;367:203-13. http://dx.doi.org/10.1056/NEJMoal 113162

5. Vickers A, Bennette C, Steineck $G$, et al. Individualized estimation of the benefit of radical prostatectomy from the Scandinavian Prostate Cancer Group Randomized Trial. Eur Urol 2012;62:204-9. http://dx.doi. org/10.1016/i.eururo.2012.04.024

6. Cooperberg MR, Cowan J, Broering JM, et al. High-risk prostate cancer in the United States, 1990-2007. World J Urol 2008;26:211-8. http://dx.doi.org/10.1007/s00345-008-0250-7

7. Lodde M, Harel F, Lacombe L, et al. Substratication of high-risk localised prostate cancer treated by radical prostatectomy. World J Urol 2008;26:225-9. httr://dx.doi.org/10.1007/s00345-008-0252-5

8. Eggener SE, Scardino PT, Walsh PC, et al. Predicting 15-year prostate cancer specific mortality after radical prostatectomy. J Urol 2011;185:869-75. http://dx.doi.org/10.1016/i.juro.2010.10.057

9. Merglen A, Schmidlin F, Fioretta G, et al. Short- and long-term mortality with localized prostate cancer. Arch Intern Med 2007;167:1944-50. http://dx.doi.org/10.1001/archinte.167.18.1944 
Fradet

10. Albertsen PC, Hanley JA, Penson DF, et al. 13-year outcomes following treatment for clinically localized prostate cancer in a population based cohort. J Urol 2007;177:932-6. http://dx.doi.org/10.1016/i. juro.2006.10.051

11. Tewari A, Divine $G$, Chang $P$, et al. Long-term survival in men with high grade prostate cancer: a comparison between conservative treatment, radiation therapy and radical prostatectomy - a propensity scoring approach. J Urol 2007;177:911-5. http://dx.doi.org/10.1016/i.juro.2006.10.040

12. Cooperberg MR, Vickers AJ, Broering JM, et al. Comparative risk-adjusted mortality outcomes after primary surgery, radiotherapy, or androgen-deprivation therapy for localized prostate cancer. Cancer 2010;116:5226-34. hittp://dx.doi.org/10.1002/cncr.25456

13. Zelefsky MJ, Eastham JA, Cronin AM, et al. Metastasis after radical prostatectomy or external beam radiotherapy for patients with clinically localized prostate cancer: a comparison of clinical cohorts adjusted for case mix. J Clin Oncol 2010;28:1508-13. http://dx.doi.org/10.1200/JC0.2009.22.2265

14. Kibel AS, Ciezki JP, Klein EA, et al. Survival among men with clinically localized prostate cancer treated with radical prostatectomy or radiation therapy in the prostate specific antigen era. J Urol 2012;187:1259-65. http://dx.doi.org/10.1016/i.juro.2011.11.084
15. Mavermann J, Fradet V, Lacombe, L, et al. The impact of solitary and multiple positive surgical margins on hard clinical end points in 1712 adjuvant treatment-naive pT2-4 N0 radical prostatectomy patients. Eur Urol. In press.

16. Mauermann J, Fradet V, Fradet Y. Adjuvant versus Salvage Radiotherapy in Patients with Positive Surgical Margins at Radical Prostatectomy: that is the Question. Eur Urol. In press.

17. Lee BH, Stephenson AJ, Czieki J, et al. Comparison of observed prostate cancer-specific mortality by treatment-specific, nomogram-predicted risks of biochemical recurrence in men with localized prostate cancer treated by radical prostatectomy, external beam radiotherapy, or brachytherapy. J Urol 2011;185:e194 (Abst 476).

Correspondence: Dr. Yves Fradet, Centre de recherche, L’Hôtel-Dieu-de-Québec, 11 côte du Palais, Québec, QC GIR 2J6; y.fradet@diagnocure.com 